\title{
Identifying the Stream Erosion Potential of Cave Levels in Carter Cave State Resort Park, Kentucky, USA
}

\author{
Brianne Spence Jacoby ${ }^{1}$, Eric Wade Peterson ${ }^{1}$, Toby Dogwiler ${ }^{2}$ \\ ${ }^{1}$ Department of Geology Geography, Illinois State University, Normal, USA \\ ${ }^{2}$ Department of Geosciences, Winona State University, Winona, USA \\ E-mail: brianne.jacoby@gmail.com,ewpeter@IllinoisState.edu,TDogwiler@winona.edu \\ Received July 8, 2011; revised August 16, 2011; accepted August 25, 2011
}

\begin{abstract}
Cave levels, passages found at similar elevations and formed during the same constant stream base level event, reveal information about paleoclimates and karst geomorphology. The investigation presented here examines how Stream Power Index (SPI) relates to cave levels. The study area, Carter Caves State Resort Park (CCSRP), is a fluviokarst system in northeastern Kentucky containing multiple cave levels. SPI determines the erosive power overland flow based on the assumption that flow accumulation and slope are proportional to potential for sediment entrainment. Part of this digital terrain analysis requires the creation of a flow accumulation raster from a digital elevation model (DEM). In creating the flow accumulation raster, one has the option to fill depressions (also considered errors) within the DEM. Filling these depressions, or "sinks," creates a well-connected stream network; however it also removes possible sinkholes from the DEM. This paper also investigates the effects a filled and an unfilled DEM have on SPI and what each reveals about erosion potential in the area. The data shows that low elevations within the filled DEM maintain a high SPI value when compared to the unfilled DEM. The filled DEM also created a stream network similar to reality. The unfilled DEM demonstrated similar SPI results between all levels, indicating a well-connected karst system. In order to truly understand the mechanics of this system, a combination of these two DEMs is required.
\end{abstract}

Keywords: Karst, Erosion, Geomorphology, Speleogenesis, Terrain Analysis

\section{Introduction}

The term karst describes terrain that contains both surficial and subterranean landforms that form through dissolution. Dissolution occurs when water, rich in carbon dioxide, dissolves the calcite in limestone or other calcium-bearing rocks and removes it through the aqueous solution [1]. The landforms produced through this process include, but are not limited to, sinkholes, cave caverns, sinking streams, and passageways. Dissolution creates a system with waterways flowing in both vertical and horizontal directions. Passage development is dependent on a variety of factors, including base flow elevation of the streams, stratigraphy, the movement of water in the unsaturated zone to underlying bedrock, chemical variations, and variations in discharge [2]. Active dissolution and extended periods of constant base level, allow for large passages to develop at or near the current base level elevation. When the regional base level lowers, river incision rates increase and groundwater flow is deflected to lower elevations [3]. Dissolution in passages that were abandoned by groundwater flow is limited or stopped as a result of this regional hydrologic change.

Cave levels are identified as a group of passages found at similar elevations. It is understood that these passages are created at the same time when the region's surface waters maintained a static base elevation. Consequently, cave levels are significant landforms left in the rock record that can help in deciphering the timing of cave system development. Multilevel cave systems contain a history of episodic lowering of the local base level in response to regional discharge changes. Deciphering where the flow has changed from predominantly horizontal flow to vertical flow is considered to be the level boundary [2]. Cave levels have been used to develop speleogenic histories of Mammoth Cave [4], the Cumberland Plateau region [3], and the Carter Caves karst area [5,6]. 
Additional insight on the evolution of karst systems provide greater understanding of the systems' complicated mechanics and are important to understanding the paleoenvironment.

Digital terrain analysis (DTA) is a quantitative GIS-based technique for analyzing topography and geomorphic processes at a variety of scales using digital elevation models (DEMs) [7]. The growth in availability of accurate high-resolution DEMs collected using LiDAR has opened up opportunities to understand and predict landscape processes related to erosion, contaminant transport, and other related phenomena. Furthermore, DTA has become a tool for studying topographicallyrelated landscape features such as soils, vegetation, and even wildlife.

DTA is based on the derivation and analysis of primary and secondary topographic attributes. Primary terrain attributes include topographic characteristics such as aspect, slope, catchment area, and profile curvature which are directly measurable from a DEM or topographic map. Secondary topographic attributes are derived by combining primary attributes mathematically. Generally, secondary attributes are indices that predict and describe the spatial variability of hydrological, geomorphological, and biological processes across the landscape [8]. Topographic attribute values are typically calculated (e.g., with Raster Calculator in ArcGIS) for each cell in the DEM raster. Thus, the accuracy and precision of the attribute derivation and their predictive power are directly related to the resolution of the DEM.

The Stream Power Index (SPI) is a secondary topographic attribute derived from slope and the contributing area of flow accumulation. Despite its name, the SPI evaluates erosive power across the whole landscape, not just in streams. By highlighting areas with large catchments and steep slopes the SPI predicts contributing areas where the erosive power of overland flow will be the highest [7]. In the absence of regional discharge data, SPI can also serve as a simple to employ surrogate for identifying areas at risk for intense stream erosion, especially in relation to high-magnitude precipitation events. Use of the SPI, as with all DTA, necessarily involves field-based verification to determine the threshold SPI values that serve as a minimum for making useful predictions about erosive potential across the landscape [9].

SPI can also be used to locate and identify the erosion potential of ephemeral gullies. Ephemeral gullies are typically observed after high-magnitude, low frequency precipitation events that trigger overland flow. In karst areas, such overland flow occurs when subsurface flow paths become inundated and excess flow is forced to follow surface flow routes. Such gullies typically "heal" between overland flows events through mass wasting processes such as creep and hill slope slump. However, subsequent flow events will often lead to re-initiation of gullying processes along the same locations. Pike et al. [10] used various terrain analyses, including SPI, to model erosion potential of ephemeral gullies and then compared those results to real-world conditions. They found that about $80 \%$ of the calculated SPI values, which were above the critical predictive threshold, successfully identified areas of observed gully formation.

Other studies that have used SPI, focus on general topics such as erosion, sediment transport, and geomorphology [8] and more specific purposes such as land classification for the military [11]. Mitas and Mitasova [12] used SPI to find areas that were at risk for erosion in order to improve erosion prevention practices. They found that variations within a terrain determine how erosion patterns will evolve over a landscape. In addition to terrain, they discussed that land cover will influence how water flow paths form.

Galzki et al. [13] used LiDAR data to identify SPI within two portions of the Minnesota River Basin; one watershed was approximately 100 square kilometers while the other was 20 square kilometers. The data were provided at a 1-meter scale, but the authors resampled the data to 3-meters in order to reduce processing time while maintaining high accuracy. The majority of the study area was of low to moderate relief. Terrain attributes are more straightforward in regions with high relief because flow routes are easier to distinguish. Therefore, more caution is required when interpreting terrain as an area's relief decreases. The authors found the previous statement to be true and concluded that the SPI predictions in areas with extremely low relief were likely unrealistic. With the results of this study, researchers identified areas that were at risk of erosion. When they ground-truthed those results, they found that out of the 15 areas visited, 14 were identified as being at risk of erosion. Seven (7) of those 14 areas contained gullies. Galzki et al. successfully identified features that could be contributing networks for transporting contaminants from agricultural fields. The results of this study are being used to bring forth water quality and conservation efforts to the area.

Carter Caves State Resort Park (CCSRP) is located in Carter County. The park consists of approximately 106 square kilometers of deeply incised valleys, characteristic of the Cumberland Plateau [14]. The elevation range in this area is between approximately 197 meters and 345 meters above sea level, with the maximum land slope being $41^{\circ}$ in the bottom of the river valleys. The Borden Formation is the oldest formation in the park, consisting of fine-grained sandstone, siltstone, and shale. The Borden Formation is considered to control the tributary 
down cutting in the area [15]. This unit is overlain by the Newman Limestone, which contains the caves the area is known for. The Newman Limestone contains the Upper Renfro Formation, the St. Louis Limestone, the St. Genevieve Limestone, and the Upper Newman Formation. These limestone formations vary in color, grain sorting, and stratigraphic structures. Capping the Newman is the Pennington Formation, which includes the Carter Caves and Lee sandstones. The Pennington Formation is the park's cliff-forming unit.

In a previous work, Jacoby et al. [5,6] used GIS, a cave database for CCSPR, and a 10-meter DEM to identify levels within CCSRP. The authors found two different options for the amount of levels within the park. Option 1 consists of four levels and Option 2 consists of five levels. Levels 1 - 3 cover the same extent for both options but Level 4, Option 1 is split into levels 4 and 5 in Option 2. Distinguishing between four and five levels is important when learning about the region's speleo- genesis. This study will use the results of Jacoby et al. [5] for the location and elevations of existing cave levels.

The project presented here is designed to take SPI application a step further. Currently, SPI research focuses on areas in erosion prevention and land classification. Here SPI is used to determine if the erosion patterns within a karst system correlate with cave levels. SPI will be applied to CCSRP in northeastern Kentucky in order to compare how erosion potential values compare to cave levels within CCSRP (Figure 1). Note that in creating a SPI dataset, one must create a stream network. This process requires a decision to be made on whether or not to fill "sinks" within the DEM. Filling sinks is a practice that removes depressions, or possible errors, within the dataset. These depressions collect water and eliminate flow from continuing downstream (Figure 2). However by filling sinks, one is assuming that all depressions are errors. Arnold [16] suggests that the size of these depresssions should be considered before they are filled. Based

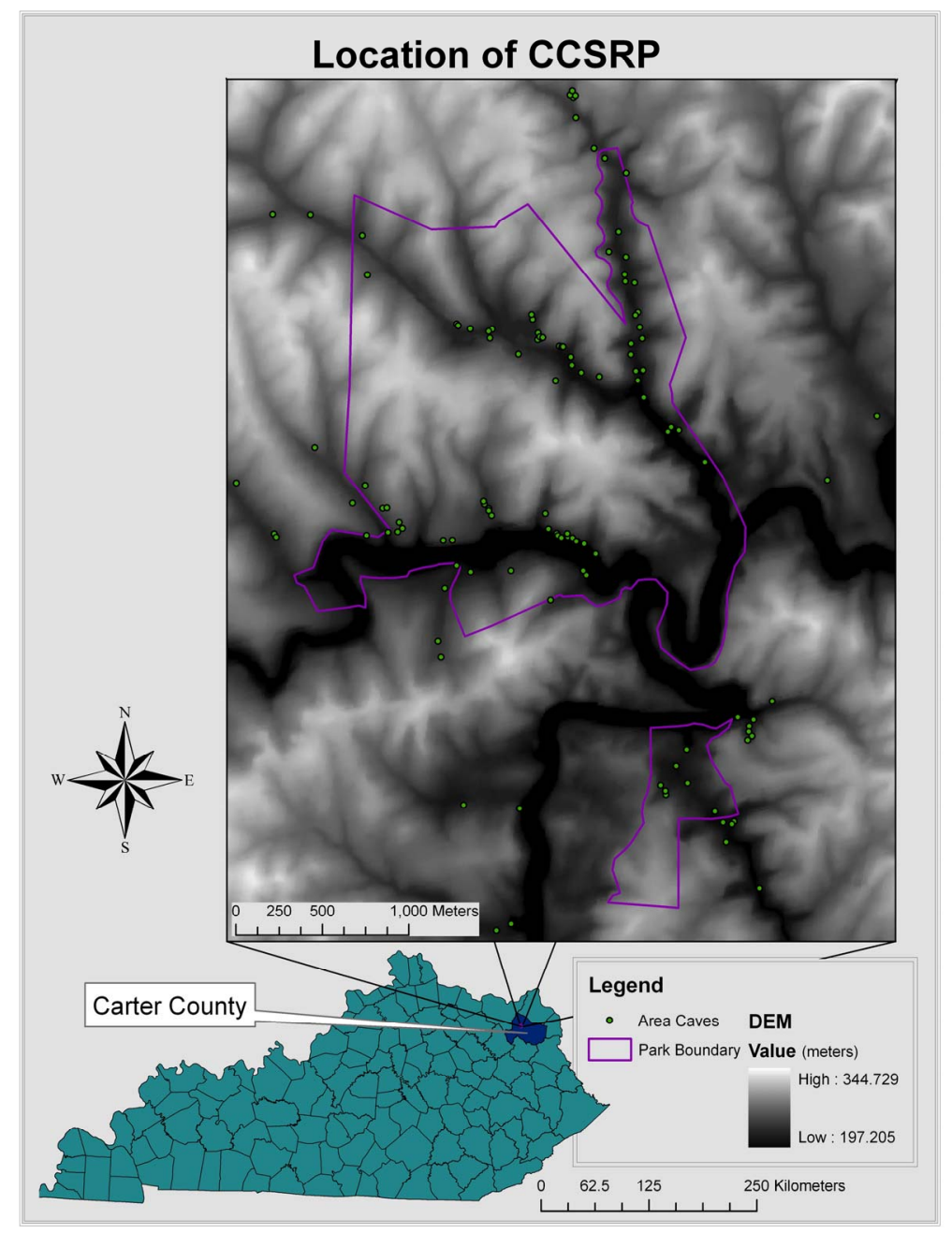

Figure 1. Location of CCSRP. Note that gray-scale image shown is only a portion of the DEM used in this study. 


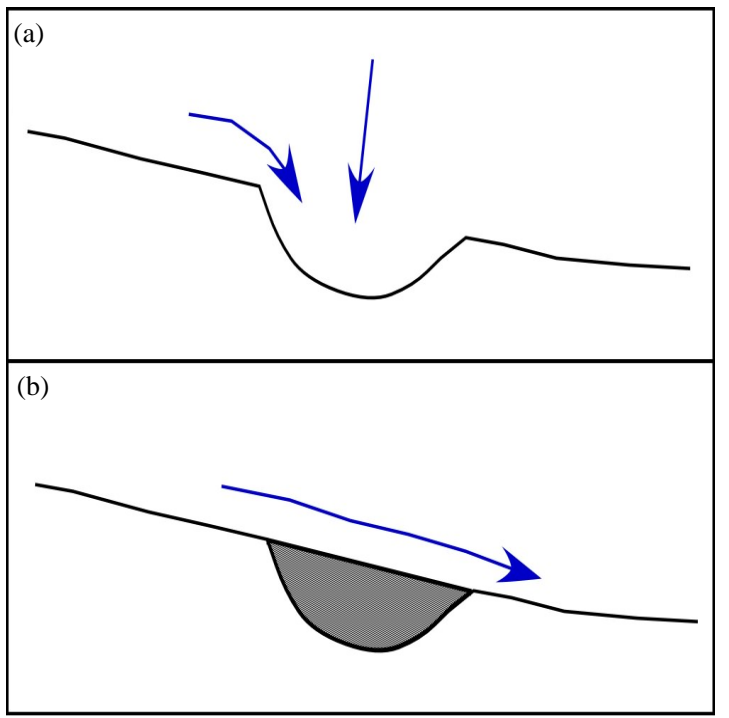

Figure 2. Schematic of how filling the DEM tool works. a) A DEM without sinks filled. Water enters the sink, but does not leave. b) A DEM with the sinks filled. Water runs over the sink and continues downstream.

on the fact that the study area is karst terrain and depressions are likely, it would be acceptable to not fill the sinks within the DEM. However by not filling the sinks, a well-connected stream network will not be created. A poorly connected stream network will result in less water accumulation downstream, and therefore, some gullies will demonstrate a smaller erosion potential than reality. In order to gain a complete understanding of how filling sinks within the CCSRP DEM will effect prediction of the region's erosion potential, there will be two different SPI datasets created; one representing erosion potential of a filled DEM and the other representing the erosion potential of an unfilled DEM. One hypothesis is that there are a smaller amount of SPI values in the unfilled DEM versus the filled DEM. This is based on the assumption that there will be less flow accumulation cells in the unfilled DEM. Another hypothesis is that there are higher SPI values in cave levels at lower elevations. Streams at lower elevations tend to be larger and have a greater amount of water moving through them at one time as compared to streams at higher elevations. This is because lower elevation streams have a larger contributing area for water.

\section{Materials and Methods}

The procedures outlined by Galzki et al. [13] and Dogwiler et al. [9] were followed for this project. A Geographic Information System (GIS) was used to perform the analysis along with the cave level elevations found by Jacoby et al. [5] and a 10-meter DEM that was down- loaded from seamless.usgs.gov. According to the National Standard for Spatial Data Accuracy (NSSDA) horizontal accuracy associated with these 10 meter DEMs is approximately \pm 13.906 meters while the vertical accuracy is approximately \pm 0.3632 meters [17]. This DEM covers an area that is approximately 73 square kilometers. The resolution of the DEM is important to consider in respect to the size of the study area. If looking at a small landscape feature such as a pasture or small farm, a high resolution DEM is required [9]. However if looking at a larger area, such as a county or state park, high resolution DEMs can provide too much detail for the area in question. It is also important to note that not all areas have high resolution DEMs or LiDAR data available. The smallest DEM resolution available for this area is 10 meters and that is why a higher resolution option was not explored.

The first step taken in this study was to create a raster that represented the elevation range of each cave level found by Jacoby et al. [5]. Six (6) rasters were created in total (Table 1): Level 1 (L1) ranging from 214 - 228 meters, Level 2 (L2) ranging from 228 - 240 meters, Level 3 (L3) ranging from 240 - 253 meters, Level 4-Option 1 (L4-Op1) ranging from 253 - 274 meters, Level 4-Option 2 (L4-Op2) ranging from 253 - 263 meters and Level 5-Option 2 (L5-Op2) ranging from 236 274 meters. The rasters were created using Equation (1):

$$
\begin{gathered}
\text { Level } i=\text { [CCSRP_DEM] }>\text { lower_range \& } \\
\text { [CCSRP_DEM] }<=\text { upper_range }
\end{gathered}
$$

where Level $i$ refers to the level (and option) of interest, CCSRP_DEM is the 10-meter DEM used for this study, lower_range is the lower elevation of the given level, and upper_range is the upper elevation of the given level (Table 1). Another raster calculation was performed to identify the area of clastic rocks overlying the limestone units. This raster included all cells that were greater than 274 meters, which is the contact elevation between the limestone and clastic units [5]. An equation similar to (1) was used, with only one reference to [CCSRP_DEM] and identified cells greater than 274 meters.

A filled DEM was then created using the "fill" tool in

Table 1. Level Elevation Ranges modified from Jacoby et al. [5].

\begin{tabular}{cc}
\hline Level & Elevation Range (m) \\
\hline L5-Op2 & $263-274$ \\
L4-Op2 & $253-263$ \\
L4-Op1 & $253-274$ \\
L3 & $240-253$ \\
L2 & $228-240$ \\
L1 & $214-228$ \\
\hline
\end{tabular}


ArcMap 9.3.1, which finds depressions within the DEM and fills those that inhibit flow downhill in order to create a realistic stream network. Next, SPI calculations for both a filled and unfilled DEM were performed using Equation (2).

$$
\text { SPI }=\text { (flow accumulation }) *(\text { slope })
$$

Flow accumulation (or upslope contributing area) summarizes the amounts of cells that flow into a single cell whereas slope represents the maximum rate of change between a cell and its neighbors. The flow accumulation raster was derived using Hydrology tools available in ESRI's ArcMap ${ }^{\mathrm{TM}}$ 9.3.1. The surface analyst tools in ArcMap ${ }^{\mathrm{TM}}$ 9.3.1 were used to derive a slope raster. All rasters were manipulated as directed by Dogwiler et al. [9] until a Raw SPI raster was determined.

Statistical analyses were performed to calculate the percentiles (1st - 99th) of the SPI data. The percentile values were brought back into the GIS to determine final SPI thresholds. The percentile range used to choose a threshold typically depends on the regional geology and geomorphology as well as the purpose of the research [9]. Researchers working in flat landscapes typically choose lower percentiles than those working in steep landscapes. The thresholds for this site were based on past experiences with SPI thresholds and knowledge of CCSRP. The thresholds presented here are a conservative guess, but they reproduce artificial stream networks created by Jacoby et al. [5]. Five thresholds were chosen with values ranging between the 99th, 98th, 97th, 96th and 95th percentiles. These values were given a threshold value of 5 through 1 respectfully, with 5 having the greatest erosion potential. A sixth threshold, value of 0 , was given to the remaining percentile values (Table 2). Note that the Raw SPI values shown below vary between the filled and unfilled DEMs. This is because the unfilled DEM had a smaller accumulation raster. Although there was this difference, the SPI thresholds are the same. Unfilled Raw SPI values of 4.38 - 8.52 represent the highest erosion potential for its DEM and are given a SPI threshold of 5 .
A larger flow accumulation raster resulted in higher Raw SPI values for the filled DEM. Raw SPI values of 5.41 12.18 represent the highest erosion potential for its DEM and are also given a SPI threshold of 5. The SPI thresholds represent the erosion risk of those cells for each DEM, regardless of how the original SPI values compare between the DEMs.

Using Equation (3), raster calculations were performed to see how many of the grid cells within each level contained the various SPI thresholds.

true Level $i$ cells \& [CCSRP_SPI] > lower_value \&

$$
\text { [CCSRP_SPI] <= upper_value }
$$

where true Level $i$ refers to the level cells of interest and CCSRP_SPI refers to the SPI raster, lower_value is the lower Raw SPI value of the SPI threshold in question, and upper_value is the upper Raw SPI value of the SPI threshold in question (Table 2). Seventy-two (72) calculations were performed in total (36 calculations per DEM).

Next, the cells within the clastic raster that contained each of the SPI thresholds were counted. Twelve (12) calculations were performed in total (6 per DEM). Equation (3) was used. Note that the variables ranged based on the clastic raster and the SPI threshold in question. The final step was to calculate the percentage of coverage of each SPI threshold within each level or clastic raster. Equation (4) was used:

$\%$ SPI threshold coverage $=[($ SPI threshold cells within

Level $i) /($ total cells within Level $i){ }^{*} 100$

where SPI threshold corresponds to the SPI threshold in question and Level $i$ refers to the level of interest.

\section{Results}

Generation of a stream network using SPI values creates a continuous network in the filled DEM (Figure 3(a)) and an irregular network in the unfiled DEM (Figure 3 (b)). These patterns are the result of different flow accumulation rasters, the filled DEM having a larger one com-

Table 2. This table outlines SPI thresholds used for this study. Note that the Raw SPI values are higher in the filled Dem than the unfilled DEM.

\begin{tabular}{cccc}
\hline SPI Threshold & Percentile & Filled Raw SPI Value & Unfilled Raw SPI Value \\
\hline 0 & 1st - 94th & $-13.82-2.87$ & $-13.82-2.49$ \\
1 & 95 th & $2.87-3.06$ & $2.49-2.78$ \\
2 & 96 th & $3.06-3.54$ & $2.78-3.14$ \\
3 & 97 th & $3.54-4.23$ & $3.14-3.62$ \\
4 & 98 th & $4.23-5.41$ & $3.62-4.38$ \\
5 & 99 th & $5.41-12.18$ & $4.38-8.52$ \\
\hline
\end{tabular}



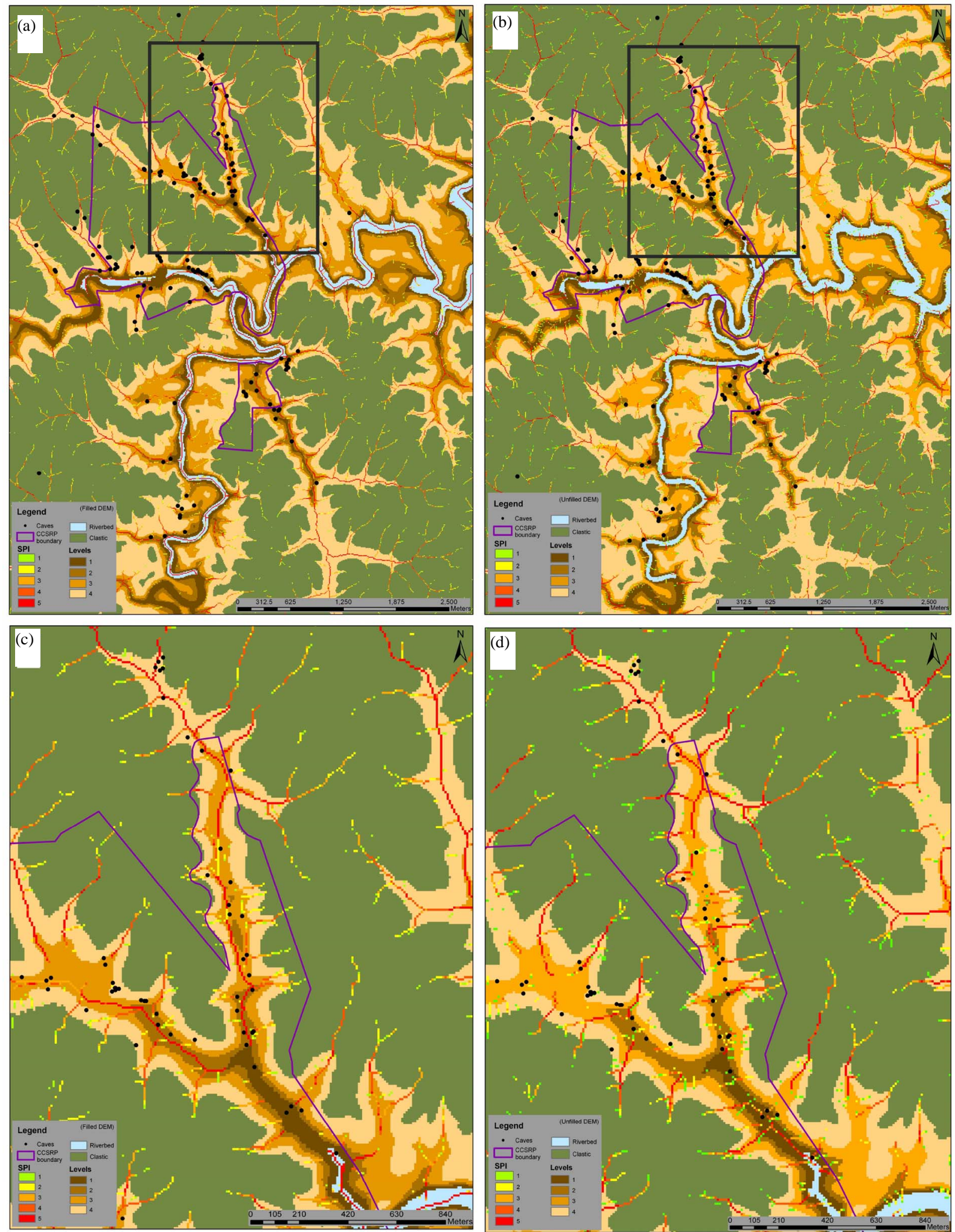

Figure 3. Visual of SPI designation using a) a filled DEM and b) an unfilled DEM. Figures c) and d) show a large scale depiction of Horn Hollow (outlined area). SPI 0 is not shown because it equates to every cell but those already classified as SPI. If it was shown, the other detail would be lost. Also note that all area depicted as "LEVELS" is also limestone. The stream network in the unfilled DEM is discontinuous compared to the filled DEM. 
pared to the unfilled DEM. In the filled DEM, SPI 5 is primarily found within existing waterways. SPI 5 in the unfilled DEM is also found in existing waterways, except the cells do not extend the full distance of the actual channel.

The difference in coverage between the filled and unfilled DEMs is evident in lower elevations of Figure 3 (closest to the riverbed). The coverage of SPI 5 in the filled DEM is greater than the unfilled DEM whereas SPI 1 has a higher coverage in the unfilled DEM than the filled DEM. Approximately $10 \%$ of the area is designated with SPI values above the 95\% threshold (Tables 3 and 4). Using the Filled DEM generates a SPI coverage that illustrates more variability than the unfilled DEM (Figure 4). However, the coverage percentages for each threshold group are rather stable among the levels. The percentages listed indicate how much of the entire level is covered by a given percentile. For example in the filled DEM, raster cell values between 5.41 and 12.18 make up the 99th percentile. Out of all the cells that constitute Level $1,5 \%$ of those are in the 99th percentile of SPI values. The coverage of SPI 5 appears to increase as level elevation decreases in the filled DEM, indicating the highest erosion potential is at the lowest elevations. The other threshold values, 1 - 4 appear to stay consistently between the $0.5 \%$ and $2.5 \%$. The percentage of area designated as SPI 0 decreases as level elevation decreases, indicating that there is smaller erosion potential at higher elevations.

The SPI coverage in the unfilled DEM does not show the same pattern as the filled DEM. The coverage of SPI 5 does decrease with elevation, but Level 2 maintains the highest percentage of coverage. Note that the percentage of coverage is overall higher in SPI 5 values within the filled DEM verses the unfilled DEM. SPI 1 - 4 values in Level 1 maintain a higher coverage percentage in the unfilled DEM than the filled DEM. Level 2 appears to have similar coverage in the filled and unfilled DEM. Level 3 has lower coverage of SPI 1 - 4 values in the unfilled DEM than the filled DEM. The coverage of SPI 1 - 4 in Level 4, Option 1, Level 4, Option 2, and Level 5, Option 2 appear to be similar in both DEMs.

Table 5 shows the coverage of SPI across the limestone and clastic units in the filled DEM while Table 6 shows the coverage of SPI across the limestone and clastic units in the unfilled DEM. Figure 5 provides a visual

Table 3. Percentage of Filled DEM SPI threshold coverage for each level.

\begin{tabular}{|c|c|c|c|c|c|c|}
\hline Level/SPI & $\begin{array}{c}-13-28.87 \\
0\end{array}$ & $\begin{array}{c}2.7-3.06 \\
1\end{array}$ & $\begin{array}{c}3.06-3.54 \\
2\end{array}$ & $\begin{array}{c}3.54-4.23 \\
3\end{array}$ & $\begin{array}{c}4.32-5.41 \\
4\end{array}$ & $\begin{array}{c}5.41-12.18 \\
5\end{array}$ \\
\hline 1 & $88.42 \%$ & $0.9 \%$ & $2.1 \%$ & $1.9 \%$ & $1.7 \%$ & $5.0 \%$ \\
\hline 2 & $89.5 \%$ & $1.1 \%$ & $1.7 \%$ & $1.7 \%$ & $2.3 \%$ & $3.7 \%$ \\
\hline 3 & $92.5 \%$ & $0.6 \%$ & $1.4 \%$ & $1.4 \%$ & $1.8 \%$ & $2.3 \%$ \\
\hline 4, option 1 & $92.6 \%$ & $0.7 \%$ & $1.5 \%$ & $1.7 \%$ & $2.1 \%$ & $1.4 \%$ \\
\hline 4, option 2 & $91.9 \%$ & $0.7 \%$ & $1.6 \%$ & $1.7 \%$ & $2.2 \%$ & $2.0 \%$ \\
\hline 5, option 2 & $93.0 \%$ & $0.7 \%$ & $1.5 \%$ & $1.8 \%$ & $2.0 \%$ & $1.0 \%$ \\
\hline
\end{tabular}

Table 4. Percentage of Unfilled DEM SPI threshold coverage for each level.

\begin{tabular}{|c|c|c|c|c|c|c|}
\hline Level/SPI & $\begin{array}{c}-13-28.87 \\
0\end{array}$ & $\begin{array}{c}2.7-3.06 \\
1\end{array}$ & $\begin{array}{c}3.06-3.54 \\
2\end{array}$ & $\begin{array}{c}3.54-4.23 \\
3\end{array}$ & $\begin{array}{c}4.32-5.41 \\
4\end{array}$ & $\begin{array}{c}5.41-12.18 \\
5\end{array}$ \\
\hline 1 & $88.7 \%$ & $2.0 \%$ & $2.0 \%$ & $2.2 \%$ & $2.0 \%$ & $3.1 \%$ \\
\hline 2 & $89.0 \%$ & $2.0 \%$ & $2.1 \%$ & $1.8 \%$ & $1.9 \%$ & $3.3 \%$ \\
\hline 3 & $92.0 \%$ & $1.3 \%$ & $1.3 \%$ & $1.4 \%$ & $1.6 \%$ & $2.5 \%$ \\
\hline 4, option 1 & $91.2 \%$ & $1.3 \%$ & $1.4 \%$ & $1.6 \%$ & $1.8 \%$ & $2.0 \%$ \\
\hline 4, option 2 & $91.2 \%$ & $1.3 \%$ & $1.4 \%$ & $1.7 \%$ & $1.9 \%$ & $2.5 \%$ \\
\hline 5, option 2 & $92.4 \%$ & $1.2 \%$ & $1.3 \%$ & $1.6 \%$ & $1.8 \%$ & $1.7 \%$ \\
\hline
\end{tabular}




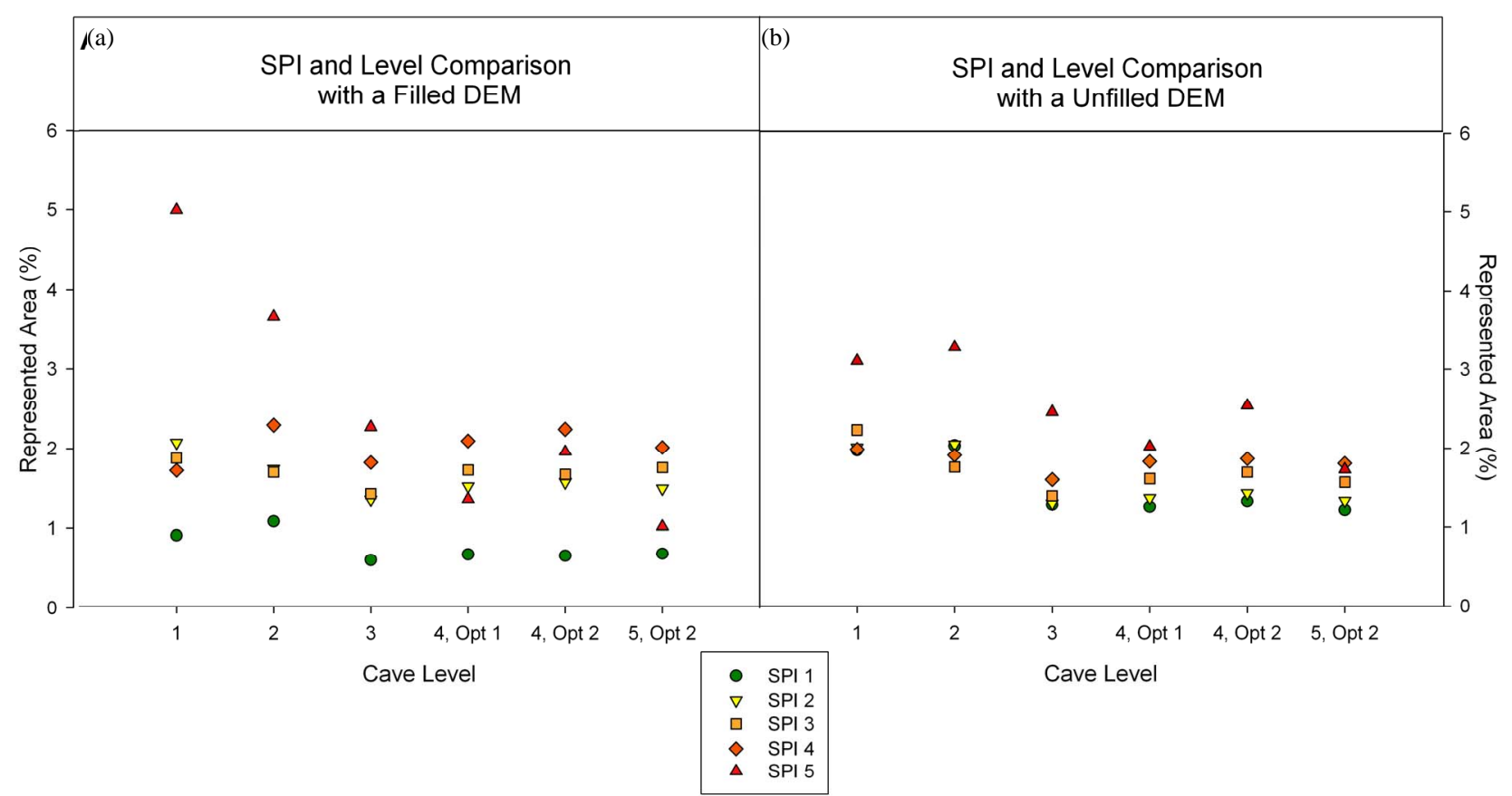

Figure 4. Graph depicting relationship between filled (a) and unfilled (b) DEMs' SPI threshold and Level. Note that Level 1 is at the lowest elevation and Level 4, Option 1 and Level 5, Option 2 are the highest in elevation.

\section{SPI and Stratigraphy Comparison}

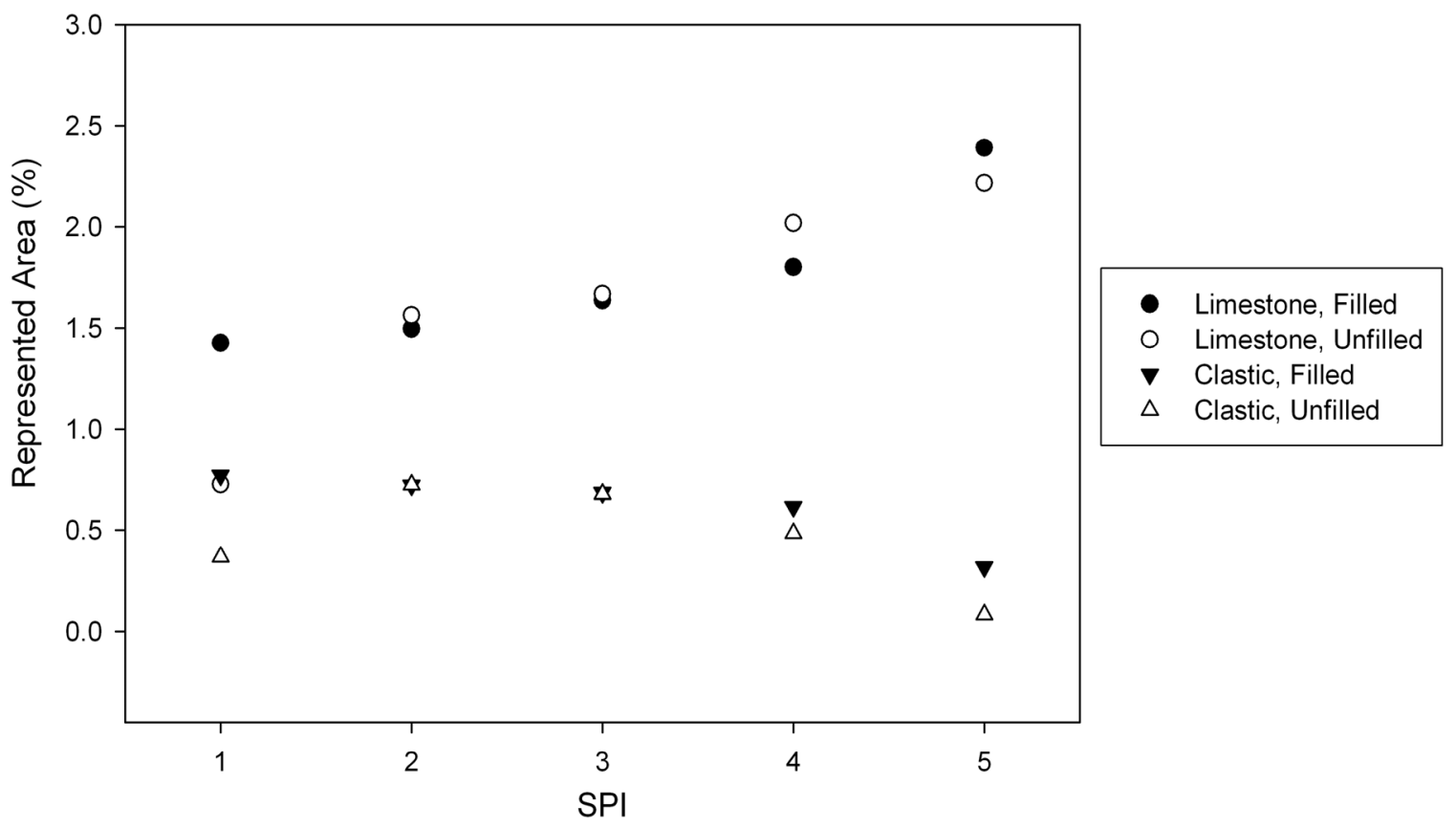

Figure 5. Graph depicting relationship between filled and unfilled DEMs' SPI threshold and the percentage of coverage.

depiction of those results. Notice how in both DEMs, the percentage of coverage increases with SPI threshold within the limestone but decreases within the sandstone.
This indicates that the limestone has a higher erosion potential. The main difference between the two DEMs is that erosion potential of the clastic rock increases slightly 
Table 5. Percentage of Filled DEM SPI threshold coverage for each unit.

\begin{tabular}{ccc}
\hline Unit/SPI & Limestone & Clastic \\
\hline $\mathbf{0}$ & $91.8 \%$ & $97.7 \%$ \\
$\mathbf{1}$ & $0.7 \%$ & $0.4 \%$ \\
$\mathbf{2}$ & $1.6 \%$ & $0.7 \%$ \\
$\mathbf{3}$ & $1.7 \%$ & $0.7 \%$ \\
$\mathbf{4}$ & $2.0 \%$ & $0.5 \%$ \\
$\mathbf{5}$ & $2.2 \%$ & $0.1 \%$ \\
\hline
\end{tabular}

Table 6. Percentage of Unfilled DEM SPI threshold coverage for each unit.

\begin{tabular}{ccc}
\hline Unit/SPI & Limestone & Clastic \\
\hline $\mathbf{0}$ & $92.3 \%$ & $96.9 \%$ \\
$\mathbf{1}$ & $1.4 \%$ & $0.8 \%$ \\
$\mathbf{2}$ & $1.5 \%$ & $0.7 \%$ \\
$\mathbf{3}$ & $1.6 \%$ & $0.7 \%$ \\
$\mathbf{4}$ & $1.8 \%$ & $0.6 \%$ \\
$\mathbf{5}$ & $2.4 \%$ & $0.3 \%$ \\
\hline
\end{tabular}

before decreasing in the filled DEM where it is a steady decrease in the unfilled DEM.

\section{Discussion}

The hypothesis that the unfilled DEM would produce smaller SPI values was proven correct based on the SPI ranges of -13 to 12.18 for the filled DEM and -13 to 8.52 in the unfilled DEM (Table 2). The other hypothesis, that higher SPI values would be found at lower elevations, also proved to be true-but with a caveat. While there was a clear relationship between high SPI values and elevation in the filled DEM; the unfilled DEM did not show as clear of a relationship. As illustrated in Figure 4, the SPI values for the region are not normally distributed. In the filled DEM, SPI 5 gradually decreases while displaying an alternating pattern in the unfilled DEM. Furthermore, the figure shows that there is not a significant difference in the coverage of SPI thresholds 2 - 4 in the filled or unfilled DEM. Level 1shows a high SPI value in the filled DEM because this area maintains a low slope and high flow accumulation. Aside from SPI 5 coverage in the unfilled DEM, the coverage of SPI 1 4 remains relatively consistent with one another. However, SPI 1 maintains a smaller coverage percentage in the filled DEM versus the unfilled DEM.

In fluviokarst the differentiation between groundwater and surface water is "fuzzy". Flow paths often sink into the subsurface (e.g., disappearing stream reaches) only to re-emerge at springs or outflows from caves. The fluvi- okarst hydrology of CCSRP is very well integrated, and this cycle of sinking and re-emergence occurs several times in many of the dominant drainages. As a result, the development and growth of subsurface flow paths (i.e., caves and conduits) controls and constrains the position of surficial erosion processes [3,4].

Considering the fluviokarst nature of the area provides insight into the SPI calculations. The filled DEM demonstrates how the water flows in regards to surface streams. The larger SPI 5 coverage at low elevations tells us that water is greatly accumulating downstream. The unfilled DEM illustrates how the regional water flows in regards to the karst geomorphology. The results from the unfilled DEM indicate a well-connected system because all levels show similar SPI coverage. It is important to keep in mind that some of the sinks within the DEM are likely errors. However, it is more likely that these sinks are direct conduits to the subsurface water network. The amount of sinks that are errors as opposed to sinkholes would have to be concluded through ground truthing. In reality it is not unusual for water to enter sinks and appear again at lower elevation discharge locations [18]. The current model does not take this into account, meaning that water exiting the cave system into the Tygarts Creek is not being shown in the results. However, the filled DEM does account for surface flow accumulation as demonstrated in the clear connection of red cells within the gray riverbed shown in the filled DEM of Figure 3. The filled DEM also excludes the presence of a karst landscape. A correct SPI study of this area would have required some combination of the two DEMs; one that included the existing sinks, but also considers surface water flow.

The clastic and limestone comparison demonstrated that high SPI thresholds are a result of stratigraphy because limestone contains a higher erosion potential when compared to clastic units. Furthermore, slope morphology is a function of stratigraphy and thus, a unit that has a high resistance to erosion will be cliff-forming and maintain low SPI thresholds. This is also demonstrated by the higher amount of SPI 0 coverage in the upper elevations (Tables 3 and 4). Figure 5 demonstrates the influence of stratigraphy and resistance to erosion because limestone shows an overall higher amount of SPI coverage than the overlying clastic rocks. The clastic units also demonstrate a low SPI threshold because they are at the highest elevation and have the smallest amount of water accumulation.

When investigating error associated with this method, grid-size resolution has to be considered. Slope is a major contributor to how well SPI calculations reflect the real world. Slope calculations are generalized over the area of each raster cell; larger cell size results in a more 
general slope calculation. Water typically gathers in channels that are smaller than the cell size. The generalized calculation and low resolution make it impossible to determine the true exact flow path within each cell [19]. This results in a possible bias within the SPI calculations. The error and bias will only be improved as higher resolution data become available. Therefore, a 10-meter DEM might not be sufficient for this study. The next step for this research is to verify SPI in the field. The groundtruthing will determine whether or not the 10-meter DEM is sufficient for the study site and provide needed insight for how to model the karst terrain while accurately depicting surface streams. Future work should investigate how the caves located within CCSRP relate to SPI. If one looks closely at Figure 3, they will notice that the caves within either image are not directly on the SPI thresholds $1-5$, meaning that SPI and cave formation do not correlate. This introduces the possibility that cave development is not dependent on erosion potential. Perhaps what is really occurring is that caves are located where there are low SPI thresholds indicating that if a gully is present (i.e. a high SPI threshold), water flows into the gully instead of entering the cave system. Caves could be located in areas that deflect water to the subsurface instead of allowing the water to flow across the ground and enter surface streams. This idea could be explored further by looking at slope and flow accumulation and comparing those results to cave openings and levels. Another investigation could concern locating bedding contacts within the limestone and seeing if SPI controls where and how well-developed level contacts are.

This research enforces what we expected to find in regards to SPI at CCSPR. Even though the current SPI study did not provide a new way to look at or interpret levels, it did confirm what we already know; that sandstone is resistant to erosion and the most stream formation is occurring in limestone. This study showed that slope and flow accumulating are important to understanding what is occurring at CCSRP. Past SPI studies have focused on improving erosion control [12] and land classification [11], but no studies have used SPI to interpret karst regions or compare flow accumulation between filled and unfilled DEMs. This study expands SPI application to geologic and geomorphic interpretation. As more studies like this are completed, the methodology and accuracy will be improved thus increasing the use of similar digital terrain analysis.

\section{Acknowledgements}

The authors would like to thank John Kostelnick with Illinois State University for his help in the GIS analysis.

\section{References}

[1] W. Dreybrodt and F. Gabrovsek, "Basic Processes and Mechanisms Governing the Evolution of Karst," Speleogenesis and Evolution of Karst Aquifers, Vol. 1, No. 1, 2003, pp. 115-154.

[2] A. N. Palmer, "Cave Levels and Their Interpretation," The NSS Bulletin, Vol. 49, No. 2, 1987, p. 50.

[3] D. M. Anthony and D. E. Granger, “A Late Tertiary origin for Multilevel Caves along the Western Escarpment of the Cumberland Plateau, Tennessee and Kentucky, Established by Cosmogenic ${ }^{26} \mathrm{Al}$ and ${ }^{10} \mathrm{Be}$,” Journal of Cave and Karst Studies, Vol. 66, No. 2, 2004, p. 46.

[4] D. E. Granger, D. Fabel and A. N. Palmer, "PliocenePleistocene Incision of the Green River, Kentucky, Determined from Radioactive Decay of Cosmogenic ${ }^{26} \mathrm{Al}$ and ${ }^{10} \mathrm{Be}$ in Mammoth Cave Sediments," GSA Bulletin, Vol. 113, No. 7, 2001, p. 825.

doi:10.1130/0016-7606(2001)113<0825:PPIOTG > 2.0.C $\underline{\mathrm{O} ; 2}$

[5] B. Jacoby, E. W. Peterson, J. C. Kostelnick and T. Dogwiler, "Approaching Cave Level Identification with GIS: A Case Study of Carter Caves," Journal of Cave and Karst Studies, in Review.

[6] B. S. Jacoby, E. W. Peterson, T. Dogwiler and J. C. Kostelnick, "Estimating Cave Level Development with GIS,” Speleogenesis and Evolution of Karst Aquifers, in Review.

[7] J. P. Wilson and J. C. Gallant, "Digital Terrain Analysis," In: J. P. Wilson and J. C. Gallant, Eds., Terrain Analysis: Principles and Applications, John Wiley and Sons, Inc, New York, 2000, pp. 1-27.

[8] I. D. Moore, R. B. Grayson and A. R. Ladson, "Digital Terrain Modeling: A Review of Hydrological, Geomorphological, and Biological Application,” Hydrological Processes, Vol. 5, No. 1, 1991, p. 3.

doi:10.1002/hyp.3360050103

[9] T. Dogwiler, D. Docker and D. Omoth, "Rush-Pine Creek Watershed Digital Terrain Analysis Overview and Procedure Guidelines: WRC Report 2010-02,” Southeastern Minnesota Water Resource Center, Winona State University, Winona, 2010.

[10] A. C. Pike, T. G. Mueller, A. Schörgendorfer, S. A. Shearer and A. D. Karathanasis, "Erosion Index Derived from Terrain Attributes Using Logistic Regression and Neural Networks,” Agronomy Journal, Vol. 101, No. 5, 2009, p. 1068. doi:10.2134/agronj2008.0207x

[11] S. D. Warren, V. E. Diersing, P. J. Thompson and W. D. Goran, "An Erosion-Based Land Classification System for Military Installations,” Environmental Management, Vol. 13, No. 2, 1989, p. 251. doi:10.1007/BF01868372

[12] L. Mitas and H. Mitasova, "Distributed Soil Erosion Simulation for Effective Erosion Prevention," Water Resources Research, Vol. 34, No. 3, 1998, p. 505. doi:10.1029/97WR03347

[13] J. Galzki, D. Mulla, N. Joel and S. Wing, “Targeting Best 
Management Practices (BMPs) to Critical Portions of the Landscape: Using Selected Terrain Analysis Attributes to Identify High-Contributing Areas Relative to Nonpoint Source Pollution,” Minnesota Department of Agriculture, 2008.

[14] A. S. Engel and S. A. Engel, "A Field Guide for the Karst of Carter Caves State Resort Park and the Surrounding Area, Northeastern Kentucky,” In: A. S. Engel, Ed., Field Guide to Cave and Karst Lands of the United States, Karst Waters Institute Special Publication 15, Karst Waters Institute, Leesburg, 2009, pp. 154-171.

[15] G. D. Ochsenbein, "Origin of Caves in Carter Caves State Park, Carter County, Kentucky,” Bowling Green State University, Bowling Green, 1974.

[16] N. Arnold, “A New Approach for Dealing with Depressions in Digital Elevation Models When Calculating Flow Accumulation Values," Progress in Physical Geo- graphy, Vol. 34, No. 6, 2010, p. 781. doi:10.1177/0309133310384542

[17] T. Blak, “DEM Quality Assessment,” In: D. F. Maune, Ed., Digital Elevation Model Technologies and Applications: The DEM Users Manual, American Society for Photogrammetry and Remote Sensing, Bethesda, 2007, pp. 425448.

[18] C. G. Groves and A. D. Howard, "Early Development of Karst Systems; 1, Preferential Flow Path Enlargement under Laminar Flow,” Water Resources Research, Vol. 30, No. 10, 1994, p. 2837. doi:10.1029/94WR01303

[19] J. C. Gallant, M. F. Hutchinson and J. P. Wilson, "Future Directions for Terrain Analysis,” In: J. P. Wilson and J. C. Gallant, Eds., Terrain Analysis: Principles and Applications, John Wiley and Sons, Inc, New York, 2000, pp. 423-427. 